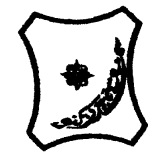

\title{
STRAIN COMPARISON ON REPRODUCTIVE PERFORMANCE, GROWTH AND SURVIVAL IN TWO WILD Clarias gariepinus (BURCHELL 1822) AND THEIR RECIPROCAL HYBRIDS
}

\author{
Umar, B. D. \\ Department of Biology, Federal College of Education, Katsina, Nigeria \\ *Corresponding Author: bashirumardayi0123@gmail.com. Tel:+2348168004506
}

\begin{abstract}
A strain comparison experiments was carried out in wild Clarias gariepinus with the aim of evaluating the reproductive performance, (in terms of percentage fertility and hatchability) growth and survival for choice of strain in selective breeding. Live samples of wild C. gariepinus collected from River Argungu, Kebbi state (KB) and Eleyele dam, Oyo state (OY), Nigeria were crossbred and mated in pure parental and reciprocal crosses generating four mating combinations (generic crosses) replicated three times in completely randomized design (CRD) manner. The $F_{1}$ generations were reared indoor for 56 days. The hybrids revealed higher characters compared to the progeny of pure parental groups in fertilization rate $(84.000 \pm 0.270 \% ; 78.265 \pm 0.135 \%$ compared to $88.400 \pm 0.130 \% ; \quad 71.465 \pm 0.265 \%)$, hatching $(77.305 \pm 0.405 \% ; 72.235 \pm 0.465 \%$ compared to $80.995 \pm 0.025 \% ; 64.555 \pm 0.615 \%$ ) and survival of larvae (100.000 $\pm 0.000 \% ; 98.582 \pm 1.418 \%$ compared to $98.840 \pm 0.581 \% ; 73.371 \pm 0.157 \%)$. On the other hand, fertilization and hatching rate among the hybrids and the pure crosses were statistically significant $(P<0.05)$. Similarly, significant difference $(P<0.05)$ was observed between the two reciprocal hybrids. However, the hybrid crosses showed intermediate characters between the pure crosses in mean weight gain (MWG), specific growth rate (SGR) and survival of fingerlings. Though the crosses of pure Oyo species displayed significantly higher value in MWG $(5.583 \pm 0.058 \mathrm{~g})$ and SGR $(10.319 \pm 0.051 \mathrm{~g})$ than other groups, fingerling survival (73.371 $0.157 \%)$ was found to be lowest. The growth parameters like MWG (4.884 $\pm 0.001 \mathrm{~g})$ and SGR $(10.231 \pm 0.130 \mathrm{~g})$ of the hybrids of Oyo fingerlings were found to be higher than pure Kebbi crosses, while survival $(100.000 \pm 0.000 \%)$ of hybrid of Kebbi fingerlings were higher than pure Kebbi $(98.840 \pm 0.581 \%)$. Therefore, this is considered as heterosis (hybrid vigour) for the hybrids they have achieved better traits either one of the pure groups. Intra-specific cross of female wild C. gariepinus from Kebbi and male wild C. gariepinus from Oyo (KB? $x$ oY ${ }^{\lambda}$ ) be practiced for optimum performance used in commercial production. This will ensure high fertility, hatchability, growth and survival rate.
\end{abstract}

Key words: Clarias gariepinus, growth, reproductive performance, Strain comparison, survival.

\section{INTRODUCTION}

Aquaculture is viewed as an important tool to close the gap between supply and demand of animal protein in Nigeria. National demand stands at 2.1 million metric tonnes per annum while national production from both capture and aquaculture stand at 800,000 tonnes (AIFP, 2014). In Nigeria about 1.3 million metric tonnes of fish are imported to meet the annual demand (FMA, 2015). Production from natural fisheries is estimated to be at a maximum sustainable level. The aquaculture system in Nigeria is largely dependent on Clariid catfishes (70 percent), tilapia, with smaller contributions from mullets and carps to total production (FAO, 2012).

Crossbreeding is used to evaluate performance and achieve improved traits (heterosis), minimize inbreeding and obtain better hybrids (Jothilakshmanan and Marx, 2013). Hybridization has also been successful in evaluating and improving reproductive traits, growth rate like daily weight gain, specific growth rate, survival rate (Hassan et al., 2011).

Fish hybridization is one of the genetic techniques which help to remove undesirable traits while retaining only the desirable ones. Fish production through hybridization is an age long practice in Africa. Hybridization in African catfishes Clarias gariepinus, Clarias anguillaris, Heterobranchus bidorsalis and Heterobranchus longifilis has been in practice in Africa (Adah et al., 2014). 
Special Conference Edition, November, 2019 Inter-specific hybridization between endemic species and introduced species or between wild and cultured populations is appearing to be a topic of great concern (Hershberger et al., 1990). This is because culture of hybrids has raised concerns regarding the introgression of Clarias gariepinus genes into local or wild fish which may have effects on genetic integrity of native species. No much intra-specific hybridization appears to have been systematically studied in pure local (wild) African catfish (C. gariepinus), (Ochokwu et al., 2015). For aquaculture to meet-up with the increasing demand for fish there is need for development of improved fish seeds that can contribute to increased fish production (Hassan et al., 2011). Clarias gariepinus is the second most important freshwater fish, after tilapia, in Africa. This is with exception of Nigeria, where C. gariepinus production exceeds that of tilapia, accounting for $70-80 \%$ of the total freshwater fish production (FAO, 2012). The level of heterosis for economically important traits is still not known with certainty. If the level of heterosis were significant, different breeding objectives could be defined to develop specialized lines for alternative crossbreeding systems. One example would be to develop a high reproductive (in terms of high fertility and hatchability) and high survival line, and a separate line selected to develop a fast growth in Clarias gariepinus. The resultant crossbreds of the two lines combining advantageous characteristics of their parents would be used in commercial production. Therefore, evaluation of reproductive performance (in terms of percentage fertility, and hatchability), survival and growth of wild $C$. gariepinus and the estimates of the percentage heterosis of $F_{1}$ generation of pure parental crosses and their hybrids would be helpful to this direction.

\section{MATERIALS AND METHODS Study Area}

The experiment was conducted in fish hatchery of the Department of Biology, Ahmadu Bello University, Zaria, Kaduna State. Zaria lies on latitude $11^{\circ} 6$ ' $18 \mathrm{~N}$ and longitude $07^{\circ} 30^{\prime} 29 \mathrm{E}$. Rainfall is between May and September with a peak in August. The average annual rainfall is about $700 \mathrm{~mm}$. The pattern of rainfall in the area is highly variable (Iguisi et al., 2012). The mean annual temperature ranges from $29^{\circ} \mathrm{C}-38^{\circ} \mathrm{C}$.

\section{Sample Collection and Broodstock Selection}

Live samples of wild C. gariepinus were collected from River Argungu, Kebbi state (KB) (within latitude $12^{\circ} 45^{\prime} 0.00^{\prime \prime} \mathrm{N}$ and longitude $4^{\circ} 30^{\prime} 60.00 " \mathrm{E}$ ) and Eleyele dam, Oyo state (OY) (within latitude $7^{\circ} 31^{\prime} 0.00^{\prime \prime} \mathrm{N}$ and longitude $\left.3^{\circ} 33^{\prime} 60.00 " \mathrm{E}\right)$. The fish samples were obtained from catches of fishermen at landing site of each sampling location. Clarias gariepinus was identified in the field using the shape and the size of the vomerine toothplate, form of the teeth situated at the upper jaw and the absence of black spots on caudal fin or any other part of the body following identification keys of Reed et al (1967) and Teugels, (2003). The mature gravid females were selected based on swollen well distended soft abdomen, reddish vent, and gentle flow of few sharp golden coloured eggs on depressing the fish abdomen using the finger. Matured males were also selected based on their reddish pointed genital papillae (Teugels 1986).

\section{Artificial Fertilization}

The fish obtained were transported in 50 litres plastic Jerry can to Fisheries and Hydrobiology Lab., Biology Department, Ahmadu Bello University, Zaria, Kaduna State. The broodstock were acclimatized in $1 \mathrm{~m}^{2}$ concrete tanks for 2 months. They were fed with coppens feed at 3\% body weight twice a day before the commencement of the experiment.

The Matured males and mature gravid females fishes were selected, sexed and separated into males and females based on examination of the genital papillae, (Teugels 1986). The male and female fishes were weighed separately using a weighing balance (Model Sartorius AG, Gottinger CP 8201). Total and Standard Lengths were measured using meter rule.

The fishes were injected based on their weight using synthetic hormone (Ovaprim). Ovaprim was administered intramuscularly (above the lateral line, towards the tail) according to the manufacturers' guides $0.5 \mathrm{ml}$ per $\mathrm{kg}$ of female fish, and $0.25 \mathrm{ml}$ per $\mathrm{kg}$ of male fish (Oyeleye and Omitogun, 2007).

After the injection the fishes were kept back into the plastic bowl containing clean water and covered with chicken mesh with appropriate room temperature $\left(28^{\circ} \mathrm{C}\right)$ and water temperature $\left(26.5^{\circ} \mathrm{C}\right)$ for 10 hours latency period as a post ovulatory maturation period and to ensure high hatching rates and low proportion of deformed larvae (Hogendoorn, 1979). After the 10 hours latency period, the milt was collected by sacrificing the male. The two testes lobes of the males were removed, well cleaned with tissue paper and kept in a labeled Petri dish. The abdomen of the females were well cleaned with tissue paper to avoid contact between the eggs and water, and then stripped of its eggs by a gentle application of pressure on the abdomen to release the eggs. 
Special Conference Edition, November, 2019

The eggs were covered in the dry, labeled Petri dish and kept with labels. Fertilization rate was determined using 750 eggs from each strain, the number of eggs was estimated using the gravimetric method (number of eggs $/ \mathrm{g}$ ). The translucent eggs containing embryonic eyes at the time of polar cap formation $10-20$ minutes after fertilization were considered fertilized and counted to estimate fertilization rate (De Graaf et al. 1995). The eggs were fertilized to generate four mating combinations (generic crosses) replicated three times in complete randomized design (CRD) manner.

Pure Parental crosses: Female Kebbi $\times$ Male Kebbi $\left(\mathrm{KB}+{ }^{\circ} \times \mathrm{KB} \uparrow\right)$ and Female Oyo $\times$ Male Oyo (OY $q \times$ OY $\delta$ ) Reciprocal crosses: Female Kebbi $\times$ Male Oyo $\left(\mathrm{KB} \propto \mathrm{x}\right.$ OY $\left.{ }^{\lambda}\right)$ and Female Oyo $\times$ Male Kebbi (OY $\&$ x KB ${ }^{\lambda}$ ). Percentage fertility of each cross was calculated using the formula: \% Fertility = (Number of fertilized eggs $\div$ Number of Extruded eggs) $x$ $100 \%$ (Adebayo, 2006)

\section{Incubation and Hatching of Eggs}

Incubation and hatching of eggs were carried in six (6) aerated tanks $(50 \mathrm{~cm} \times 35 \mathrm{~cm} \times 30 \mathrm{~cm})$ containing clean kakabans (substrate attachment of eggs). Both the parental and the intra- specific crosses were replicated three times. The fertilized eggs were evenly spread on the kakaban in the tank at temperatures between $26-27^{\circ} \mathrm{C}$. The percentage hatchability was determined by identifying the healthy developing eggs (fertilized eggs) which were transparent green brownish in colour while the dead eggs (unfertilized eggs) which became white in colour were also estimated: \% Hatchability $=$ (Total number of fertilized eggs Total number of unfertilized eggs) $\div$ Total number of fertilized eggs $\times 100 \%$ (Adebayo, 2006).

\section{Setting of Indoor Experiment and Daily Survival of Hatchlings}

The experiment was set up for 56 days indoor. The life cycle of the development begins with the fertilized egg to the fingerling stages at which the rearing period indoor ends. The larvae are considered after yolk sac absorption i.e. on $4^{\text {th }}$ day to 14 days (Two weeks) (Viveen et al., 1986). The fry is considered from day $15-28$ and the fingerling is considered from day 29 - day 56 .

Four days after the hatching, when all yolk reserve had been re-absorbed, feeding of the new hatchlings with Artemia was started for 2 weeks. The fry were fed with Coppen's feed of $0.2-0.3 \mathrm{~mm}$ thrice per days for 1 week and 0.3 - $0.5 \mathrm{~mm}$ for another 1week twice per day (morning and evening) at a daily rate of $6 \%$ of fish biomass. Sampling for weight and length were done biweekly for 8 weeks.

Uneaten feeds were siphoned from the base of the aquaria every day before feeding to prevent fouling. About $25 \%$ of the culture water was always replaced every morning in order to eliminate shock and enhance survival of cultural organisms (Peter, 1987). Water temperature, dissolved oxygen and $\mathrm{pH}$ were monitored every day to maintain the quality of water. Water temperatures ranged between 26$30{ }^{\circ} \mathrm{C}$, dissolved oxygen 6.3-7.6 $\mathrm{mgL}^{-1}$, pH 6.87.5 throughout the experimental period (indoor) from larval to fingerling stages and the values were within the recommended range for rearing catfishes (Madu et al, 1984; Ayokanmi, 1999). The survival of larvae, fry and fingerlings in each bowl per treatment were taken on a daily basis for 56 days. Survivability evaluation was done for each stage of development.

\section{Determinations of Growth Performance and Survival Rate}

The growth performance of the larvae, fry, and fingerlings were determined in terms of mean weight gain (MWG), specific growth rate (SGR) and mean length gain (MLG) parameters. Measurements were carried out fortnightly for weight (to the nearest $\mathrm{g}$ ) with an electric balance and total length TL (to the nearest $\mathrm{mm}$ ) for larvae, fry and fingerlings from each treatment (breed). Length gain, weight gain and specific growth rate (SGR) were determined by formula adopted from Adebayo (2006): Weight gain = Mean final body weight (MFW) - mean initial body weight (MIW); Length gain (MLG) = Mean final length (MFL) - mean initial length (MIL); SGR $=\{$ (In W2 final weight-In W1 initial weight)/culture period\} $\times 100$ Where W1 is the initial fish weight ( $\mathrm{g}$ ) at time T1 (day) and W2 is the final fish weight at time T2 (day).

The rate of survival at each stage (two weeks for larvae and two weeks for fry and one month for fingerlings) was determined by counting and recording the survival at the beginning and end of each stage. It was calculated by the formula adopted by Adebayo (2006) as follows: Survival Rate (\%) = Final Number alive at each stage $\div$ Total Number alive counted at each stage $\times 100$

Heterosis Estimation

Heterosis is here referred to the performance both in terms of growth or survival of the hybrids relative to that of their parental offspring expressed in percentage. 
Special Conference Edition, November, 2019

The mean weight, specific growth rate and survival of the intra-specific hybrids and the parental species were used to estimate heterosis adopted by Akinwande et al., (2011). Where $C_{1}$ and $C_{2}$ is the mean weight and specific growth rate or survival of hybrids, respectively while $P_{1}$ and $P_{2}$ is the mean weight and specific growth rate or survival of parents, respectively

Heterosis \% $\left.=\left[\left(\mathrm{C}_{1}+\mathrm{C}_{2}\right) / 2\right)-\left(\mathrm{P}_{1}+\mathrm{P}_{2} / 2\right)\right] \div\left(\mathrm{P}_{1}+\right.$ $\left.\mathrm{P}_{2}\right) / 2 \times 100$

\section{Data Analyses for Hybridization Experiment}

Data collected during the study was analysed using Minitab 14 software for descriptive statistics and Genstat Discovery edition 4 for analysis of variance (ANOVA). Reproductive and growth performance was analysed using one way ANOVA followed by Duncan's multiple range tests to determine significant differences among means $(p<0.05)$, and to rank significantly different means, respectively.

\section{RESULTS}

The hybrids showed intermediate values between the two parental line crosses for fertilization. The maximum value for mean fertilization rate $(88.400 \pm 0.130 \%)$ was recorded in pure Kebbi strain of $C$. gariepinus (KB $+\times \mathrm{KB} \quad$ ) , whereas the minimum value $(71.470 \pm 0.270 \%)$ was observed in pure Oyo strain (OY $q \mathrm{x}$ OY $\delta^{\Uparrow}$ ) (Table 1.). The data analysis showed significant difference $(P<0.05)$ among all the crosses. The hybrids of female Kebbi and male Oyo (KB $q \times$ OY $\precsim$ ) recorded greater value $(84.00 \pm 0.270 \%)$ for fertilization compared to $78.270 \pm 0.14 \%$ that of its reciprocal hybrids of female Oyo (OY $q \times \mathrm{KB}$ స).

The hatching rate $77.310 \pm 0.41 \%$ for the hybrids of female Kebbi (KB $q \times$ OY $\hat{0}$ ) and $72.240 \pm 0.47 \%$ for female Oyo (OY $q$ x KB ${ }^{\top}$ ) were higher than pure Oyo $(64.560 \pm 0.620 \%)$ but lower than pure Kebbi $(81.00 \pm 0.030 \%)$ Table 1. Likewise, the value recorded in both hybrids for hatching rate was between the two parental line crosses and the data analysis show significant difference $(P<0.05)$ among and between the hybrids and the pure lines Table 1.

Table 1. Mean Percentage of Fertilization and Hatching in pure parental line of C. gariepinus from

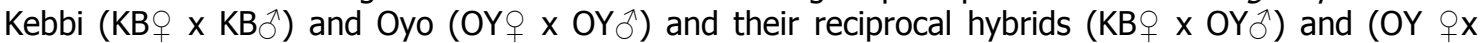
$\left.\mathrm{KB}{ }^{\top}\right)$

\begin{tabular}{|c|c|c|}
\hline Combination of Crosses & Fertilization (\%) & Hatching (\%) \\
\hline $\mathrm{KB} \odot \times \mathrm{KB}^{\lambda}$ & $88.400 \pm 0.130^{a}$ & $80.995 \pm 0.025^{a}$ \\
\hline OYO x OY & $71.4650 \pm 0.265^{b}$ & $64.555 \pm 0.615^{b}$ \\
\hline $\mathrm{KB}+\times \mathrm{OY}^{\hat{\sigma}}$ & $84.000 \pm 0.270^{c}$ & $77.305 \pm 0.405^{c}$ \\
\hline OY $\odot \times$ KB ${ }^{\lambda}$ & $78.265 \pm 0.135^{d}$ & $72.235 \pm 0.465^{d}$ \\
\hline
\end{tabular}

Values represent mean $\pm \mathrm{SE}$; Mean values in a column under each parameter bearing different superscripts $(a, b, c$ and d) differ significantly $(P<0.05)$; N.B: In any combination of crosses the first set is for females and the second is for males throughout the text.

Fishes produced from all the breeding trails increased in weight during the rearing period. The mean specific growth rate (SGR) was also high $(10.319 \pm 0.51 \mathrm{~g})$ in pure Oyo (OY o $\mathrm{x}$ OY 3 ) followed $(10.260 \pm 0.023 \mathrm{~g})$ by the hybrids of female Kebbi (KBథ $x$ OY $\lesssim$ ) fingerlings. The lowest value $(8.131 \pm 0.092 \mathrm{~g})$ was recorded in the pure $\mathrm{Kebbi}(\mathrm{KB}+\mathrm{x} \mathrm{KB} \hat{\jmath}$ ) showing significant difference compared to the other crosses $(P<0.05)$. It is clear from the result that the hybrids of female Kebbi performed better than its reciprocal hybrids of female Oyo fingerlings. Also, the statistical analysis did not show significant difference $(P>0.05)$ between the hybrids and the pure $C$. gariepinus from Oyo indicating that Specific Growth Rates of the hybrids were similar to that of the fast growing pure C. gariepinus fingerlings from Oyo (Table 2.).

Table 2. Growth performance of fingerlings of the four crosses in terms of weight fortnightly taken for a rearing period of 56 days (indoor).

\begin{tabular}{|c|c|c|c|c|}
\hline \multicolumn{5}{|c|}{ Combination of Crosses } \\
\hline Growth Parameters & $\mathrm{KB} \odot \times \mathrm{KB}^{\wedge}$ & OYO x OY & $\mathrm{KB}+\mathrm{x} \mathrm{OY}{ }^{\lambda}$ & $\mathrm{OY} O \mathrm{XKB}$ \\
\hline $\operatorname{MIW}(g)$ & $0.013 \pm 0.000^{a}$ & $0.017 \pm 0.000^{b}$ & $0.016 \pm 0.000^{b}$ & $0.016 \pm 0.001^{b}$ \\
\hline MFW(g) & $1.267 \pm 0.033^{a}$ & $5.600 \pm 0.058^{b}$ & $4.900 \pm 0.058^{c}$ & $4.900 \pm 0.000^{c}$ \\
\hline $\operatorname{MWG}(g)$ & $1.253 \pm 0.034^{\mathrm{a}}$ & $5.583 \pm 0.058^{\mathrm{b}}$ & $4.884 \pm 0.057^{c}$ & $4.884 \pm 0.001^{c}$ \\
\hline $\operatorname{SGR}(g)$ & $8.131 \pm 0.092^{a}$ & $10.319 \pm 0.051^{b}$ & $10.260 \pm 0.023^{b}$ & $10.231 \pm 0.130^{b}$ \\
\hline
\end{tabular}

Values represent mean $\pm \mathrm{SE}$; Mean values in a row under each parameter bearing different superscripts differ significantly $(\mathrm{P}<0.05)$. 
Special Conference Edition, November, 2019

During the indoor rearing period, survival rate for all combinations of crosses from larval to fingerling stages are given in Table 3. Hybrids at their larval stage of development recorded the lowest survival and showed significant difference $(P<0.05)$ from the parental crosses. During this period the highest survival was in pure Oyo followed by pure Kebbi. Although percentage survival of hybrid fry was higher $75.47 \pm 0.85 \%$ and $75.90 \pm 0.29 \%$, it recorded lower than pure parental groups $79.38 \pm 1.50 \%$ and $76.72 \pm 0.10 \%$. But in the subsequent developmental phase of the fingerlings, survival performance of the hybrids was much achieved and exceeded over the control groups significantly $(P<0.05)$. In this stage the highest $(100 \pm 0.00 \%)$ was observed in hybrids of female Kebbi crosses $\left(\mathrm{KB}+\mathrm{x}\right.$ OY $\left.{ }^{\top}\right)$ followed $(98.84 \pm 0.58 \%)$ by pure Kebbi (KB $\left.\bigcirc \times \mathrm{KB}^{\lambda}\right)$ (Table 3.). Moreover, in both the hybrids there was no significant difference $(P>0.05)$ in survival of fingerlings.

Table 3: Percentage Survival of Kebbi, Oyo strains, hybrids of female Kebbi and hybrids of female Oyo fortnightly taken from larval to fingerling stage

\begin{tabular}{|c|c|c|c|c|}
\hline \multicolumn{5}{|c|}{ Survival \% } \\
\hline Culture stage & $\mathrm{KB}+\mathrm{KB}^{\top}$ & OY $\mathrm{XYYY}^{\wedge}$ & $\mathrm{KB}+\times \mathrm{OY} \widehat{0}$ & OY $P \times \mathrm{KB} \hat{\bigcirc}$ \\
\hline Larvae & $74.33 \pm 0.88^{c}$ & $77.33 \pm 0.33^{\mathrm{d}}$ & $70.66 \pm 0.66^{b}$ & $66.66 \pm 0.66^{\mathrm{a}}$ \\
\hline Fry & $79.38 \pm 1.50^{b}$ & $76.72 \pm 0.10^{\mathrm{ab}}$ & $75.47 \pm 0.85^{\mathrm{a}}$ & $75.90 \pm 0.29^{\mathrm{a}}$ \\
\hline Fingerling & $98.84 \pm 0.58^{b}$ & $73.37 \pm 0.15^{\mathrm{a}}$ & $100.00 \pm 0.00^{b}$ & $98.58 \pm 1.41^{\mathrm{b}}$ \\
\hline
\end{tabular}

Values represent mean $\pm \mathrm{SE}$; Mean values in a row under each parameter bearing different superscripts differ significantly $(P<0.05)$

Water temperature, dissolved oxygen and $\mathrm{pH}$ were monitored every weekly to maintain the quality of water. Water temperatures ranged between $26-30{ }^{\circ} \mathrm{C}$, dissolved oxygen 6.3-7.6 $\mathrm{mgL}^{-1}$, pH 6.8-7.5 throughout the experimental period (indoor) from larval to fingerling stages. And the values were within the recommended range for rearing catfishes (Ayokanmi, 1999).

In the case of heterosis in terms of weight gain $(+7.898 \%)$, specific growth rate SGR $(+1.261 \%)$ was positive and survival performance $(-9.450 \%)$ for larvae was negative for intraspecific hybrids compared with parental crosses while for growth in terms of weight gain $(+42.891 \%)$, SGR $(+11.062 \%)$ and performance in survival of fingerlings $(+15.313 \%)$ at the end of the rearing period of 56 days (indoor) was positive for intraspecific hybrids as shown in Table 4. In addition, hybrids at the fingerlings showed superior performance of growth rate and survival (Tables 3 and 4.) indicating that the acquiring of hybrid vigor for such traits appears to exist better in advanced (later) development stage rather than in earlier stage (larvae).

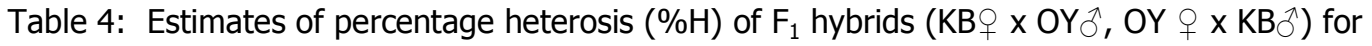
reproductive, growth and survival traits during indoor rearing period of 56 days

\begin{tabular}{cccccccc}
\hline Age(days) & Crossbred & \multicolumn{7}{c}{ Trait } \\
& & \multicolumn{7}{c}{ Fertility } & Hatchability & MWG & SGR & Survival \\
\hline 0 & KB $\times$ OY $(\% \mathrm{H})$ & +1.50 & +2.741 & - & - & - \\
14 & KB $\times$ OY $(\% \mathrm{H})$ & - & - & +7.898 & +1.261 & -9.450 \\
28 & $\mathrm{~KB} \times$ OY $(\% \mathrm{H})$ & - & - & +10.397 & +0.081 & -2.972 \\
42 & $\mathrm{~KB} \times$ OY $(\% \mathrm{H})$ & - & - & -0.636 & +4.128 & -1.126 \\
56 & $\mathrm{~KB} \times$ OY $(\% \mathrm{H})$ & - & - & +42.891 & +11.062 & +15.313 \\
OVERALL & $\mathrm{KB} \times$ OY $(\% \mathrm{H})$ & +1.50 & +2.741 & $+15.138 \pm 9.548$ & $+4.133 \pm 2.461$ & $+0.441 \pm 5.269$ \\
\hline
\end{tabular}

MWG, SGR represent Mean Weight Gain, Specific Growth Rate, respectively.

\section{DISCUSSION}

Although fertilization rate achieved in the hybrids was high $(84.000 \pm 0.270 \%$ and $78.27 \pm 0.140 \%$ ) for $\mathrm{KB}+\mathrm{x}$ OY ${ }^{\lambda}$ and $\mathrm{OY}$ 早 $\mathrm{x}$ $\mathrm{KB} \hat{\mathrm{O}}$, respectively, it recorded intermediate value between the parental crosses. The hatching rate also followed the same trend as fertilisation rate and recorded the intermediate value in the hybrids (Table 3.). Similar variation between fertilisation and hatching rates in hybrids and pure parental crosses were also made by various authors (Chaudhuri, 1961; Adebayo, 2006).

The results of growth in both hybrids for MWG and SGR were intermediate between the two parental line groups and showed superiority over Kebbi crosses. This was similar with earlier studies which reported an intermediate growth performance of the parents for $F_{1}$ hybrids and its reciprocal crosses. 
Special Conference Edition, November, 2019

Jothilakshmanan and Marx (2013) reported intermediate growth for hybrids of Hetropneustes longifilis and Clarias batrachus. In this study the values of heterosis for growth and in terms of weight gain was positive $(+7.898 \%)$ for the intraspecific hybrids. Heterosis for SGR was also recorded positive (+1.261\%). Similarly, Akinwande et al. (2011) reported positive heterosis for the interspecific hybrids of Clarias gariepinus and Clarias anguillaris. On the other hand, Ataguba et al. (2010) reported negative heterosis for growth $(-42 \%)$ in the hybrids of $C$. gariepinus and Heterobranchus longifilis after 56 days of larval to fingerling rearing. In our observation, the values for pure Oyo (OY $q \mathrm{x}$ OY $\left.\delta^{\lambda}\right)$ were significantly $(P<0.05)$ higher than the other crosses and this result was in agreement with other studies (Adewolu et al., 2008).

In the current study, a significantly higher survival was achieved in both hybrids over the parental groups during fingerling stages over the parental groups which could be attributed to improved hybrid vigour. This is in agreement with the findings of earlier reports which indicated that hybrids in most cases were superior to the parental strains (Madu et al., 1993; Salami et. al., 1993). In the present study, heterosis for survival of fingerlings in the hybrids was positive $(+15.313 \%)$. On the other hand, survival of larvae recorded was low in both the hybrid crosses and varied significantly $(P<0.05)$. The effect of hybridization to lower performance of survival is also claimed by the report of other researchers (Sahoo et al., 2003; Owodeinde et al., 2012). Similarly, Jothilakshmanan and Marx (2013) in the hybrids of Hetropneustes longifilis and Clarias batrachus reported reduced survival (0.8 and $0.9 \%$ ) due to high rate of mortality of the hatchlings when the transition from endogenous to exogenous feeding took place.

Hatchlings and survival of larvae in Oyo strain were recorded significantly higher than the other groups but the progeny of these crosses exhibited a decline trend in survival when advanced towards fry and fingerlings phases while other group crosses achieved progress in survival at its subsequent developmental stages. During the study period, the pure Kebbi progenies which were poor in survival at initial stages significantly improved and progressed in its survival performance better than pure Oyo and showed similarity to the hybrids without significant variation at the end of the experiment. This might have been related with its improved adaptability. This is supported by the improved survival percentage recorded as each group of progenies passed through the successive developmental stages. This finding is in agreement with the report of Tilahun et al., (2016) for the hybrids of female C. batrachus $\left(\mathrm{Cb}+\mathrm{x}^{-1} \mathrm{Cg}^{\lambda}\right)$ that achieved better than the pure batrachus in India.

The study revealed that the hybrids achieved better than the pure parental groups in reproductive traits (fertility and hatchabilty) and in growth and survival due to dominance and epistasis gene effect in indoor experiment except the low survival performance of the larvae recorded with a negative percentage of heterosis. This allowed selection to be made from hybrids with maternal dominance.

\section{CONCLUSION AND RECOMMENDATIONS}

The hybrids showed intermediate values of all traits performance between the two parental lines with higher performance in female Kebbi $\left(\mathrm{KB}_{+} \times \mathrm{OY}^{\lambda}\right)$ than female Oyo $\left(\mathrm{OY}_{+} \times \mathrm{KB}^{\lambda}\right)$. The study also revealed that the hybrids achieved better than the pure parental groups in reproductive traits (fertility and hatchabilty) and in growth and survival in indoor experiment except the low survival performance of the larvae recorded with a negative percentage of heterosis. It concluded that the intra-specific hybrids achieved combined improved traits in reproductive (fertility, hatchability), growth and survival with higher combine improved traits performances in hybrids of female Kebbi and Male Oyo, $\left(\mathrm{KB}+\times\right.$ OY $\left.{ }^{\prime}\right)$.

Intra-specific cross of female local $C$. gariepinus from Kebbi and male local C. gariepinus from Oyo $\left(\mathrm{KB}+\times \mathrm{OY}_{0} \hat{)}\right)$ be practiced for optimum performance. This will ensure high fertility, hatchability, growth and survival rate. This result should therefore be used as baseline information that is extended to hatchery operators and growth out farm. Further improvement for the poor survival of the larvae is require as to produce sufficient seed for grow-out culture to exploit the potential of the hybrids in aquaculture. Finally, application of selective breeding for the genetic improvement of this wild $C$. gariepinus utilizing female Kebbi and Male Oyo, $\left(\mathrm{KB}+\times \mathrm{OY}^{\Uparrow}\right)$ is also recommended. 
Special Conference Edition, November, 2019 REFERENCES

Adah, P. M. Onyia, L.U., and Obande, R. A. (2014). Fish Hybridization in Some Catfishes: A Review. Biotechnology, $13: 248-251$.

Adebayo, O. T., (2006). Reproductive performance of African Clariid Catfish Clarias gariepinus broodstock on varying maternal stress. Journal of Fisheries International 1 (1-2): 17-20.

Adewolu, M.A., Ogunsanmi A.O. and Yunusa, A.,(2008). Studies on Growth Performance and Feed utilization of two clariid catfish and their hybrid reared under different culture systems. European Journal of Science Resources 23 (2): 252-260.

Akinwande, A.A., Fagbenro, O.A. and Adebayo, O.T., (2011). Growth and heterosis in reciprocal Clarias hybrids between Clarias gariepinus and Clarias angularis. Journal of Fisheries International 6 (3): 67-70.

Aquaculture and Inland Fisheries Project (AIFP), (2014). Inventory of fish farms in Nigeria. Technical report (Annex II) of the Nigerian Special Programme for Food Security (NSPFS), $148 \mathrm{p}$.

Ataguba G. A., Annune P. A. and Ogbe F. G. (2010). Induced breeding and early growth of progeny from crosses between two African clariid fishes, Clarias gariepinus (Burchell) and Heterobranchus longifilis under hatchery conditions. Journal of Applied Bioscience. 14:755-760.

Ayokanmi, A.D. and Chukat T.M., (1999). Clarias gariepinus (B), Clarias anguillaris (L), Heterobranchus bidorsalis (G), Hereteroclarias, Clariabranchus and Chirlas Hybrids under outdoor nursery management system.

Chaudhuri, H., (1961). Spawning and hybridization of Indian carps. Proceedings of Pacific Science Congress, Abstract pp 10.

De Graaf G., Galemoni F. and Banzoussi B. (1995). Artificial reproduction and fingerlings production of African catfish, Clarias gariepinus. (Buchel 1822), in reported and protected ponds. Aquaculture Resource 26:233-242.

FAO, (2012). Cultured Aquatic Species Information Programme. Clarias gariepinus. Text by Pouomogne, V. In: FAO Fisheries and Aquaculture.

Federal Ministry of Agriculture FMA, (2015). Bridging the fish demand, supply gap in
Nigeria. Daily trust Newspaper published Tuesday, October 04, 2016.

Hassan, A., Ambak M.A. and Samad A.A., (2011). Crossbreeding of Pangasianodon hypophthalmus (Sauvage, 1878) and Pangasius nasutus (Bleeker, 1863) and their larval development. Aquaculture., 74: $1-10$.

Hershberger, W. K., Meyers, J. M., McAuley, W. C. and Saxton, A. M., (2006). Genetic changes in growth of coho salmon (Oncorhynchuskisutch) in marine net pens, produced by ten years of selection. Aquaculture, 85: 187-197.

Hogendoorn H. (1979). Controlled propagation of the African catfish, Clarias lazera ( $\mathrm{C} \&$ V).I. Reproductive biology and field experiments. Aquaculture Vol. 17 pp. 323-333

Iguisi, E. O., Abaje, I. B. and Ati, O. F. (2012). Changing climatic scenarios and strategies for drought adaptation and mitigation in the Sudano-Sahelian Ecological Zone of Nigeria. In M. A. Iliya \& I. M. Dankani (Eds.), Climate Change and Sustainable Development in Nigeria. Ibadan: Crown F. Publishers, 99-121.

Jothilakshmanan, N. and Karal Marx, K. (2013). Hybridization between Indian catfish, female Hetropneustes fossilis (Bloch) and Asian catfish, male Clarias batrachus (Linn). 12 (9): 976981. doi:10.5897/AJB11.3215

Madu, C.T., Mohammed, J. Issa and Ita, E. O. (1993). Further studies on the growth, morphormetrics and meristics characteristics of Clarias anguillaris and Heterobranchus bidorsalis and their hybrids. National Institute for Freshwater Fisheries Research Annual Report, New Bussa, pp: 23 - 29.

Ochokwu, I. J., Apollos, T.G and Oshoke, J.O. (2015.). Effect of Egg and Sperm Quality in Successful Fish Breeding, IOSR Journal of Agriculture and Veterinary Science (IOSR-JAVS) 8(8): 48-57.

Owodeinde, F.G., Fakoya K.A, and Anetekhai, M.A., (2012).Growth performance of hybrid catfish (Clarias gariepinus $\mathrm{x}$ Heterobranchus bidorsalis) in earthen ponds. Asian Journal of Biological Sciences, 5: 192-200.

Oyeleye, O. O and Omitogun, O. G. (2007). Evaluation of motility of the short-term cryopreserved sperm of African giant catfish (Clarias gariepinus). Ife Journal of Agriculture Vol. 22 .No.(1) pp.11-16. Ile-Ife, Nigeria. ISSN 0331-6351 
Special Conference Edition, November, 2019

Reed, W., John, B., Hopson, A., Jonathan, J. and Yaro, J., (1967). Fish and fisheries of Northern Nigeria (First Edition). Published b Ministry of Agriculture Northern Nigeria. 226pp.

Sahoo S.K, Giri S.S., Sahu A.K and Ayyappan S., (2003) Experimental Hybridization between Catfish Clarias batrachus (Linn.) x Clarias gariepinus (Bur.) and Performance of the Offspring in Rearing Operations. Asian Fisheries Science 16, 157-166.

Salami, A.A., Fagbenro, O.A., and Sydenham, D.H.J. (1993): The production and Growth of Clarrid Catfish Hybrids in concrete tanks. The Israeli Journal of Aquaculture-Bamidgeh, 45(1): 18-25.
Teugels G.G. (1986). Morphology Data of Clarias gariepinus, Identification Keys. http://fishbase.sinica.edu.tw/physiology/ MorphDataSummary.

Teugels, G.G. and Adriaens, D. (2003). Taxonomy and phylogeny of Clariidae: An overview. In: G Arratia, BG Kapoor, $M$ Chardon, R Diogo (Eds.), Catfishes. Science publishers, Inc., Enfield (USA). 1: 465-487.

Tilahun, G., Dube, K., Chtruvedi, C.S., and Kumar, B. (2016). Assessment of Reproductive Performance, Growth and Survival of Hybrids of African Catfish (Clarias gariepinus) and Indian Catfish (Clarias batrachus) Compared to Their Parental Lines Crosses. Turkish Journal of Fisheries and Aquatic Sciences, 16:123-133.

Viveen, W.J., Richtor, C.J., Van Ordt, P.G., Janseen, J.A. Huisman, E.A., (1986). Practical manual for culture of the African catfish (Clarias gariepinus). Section for research and technology. The Hague, The Netherlands, pp 121. 